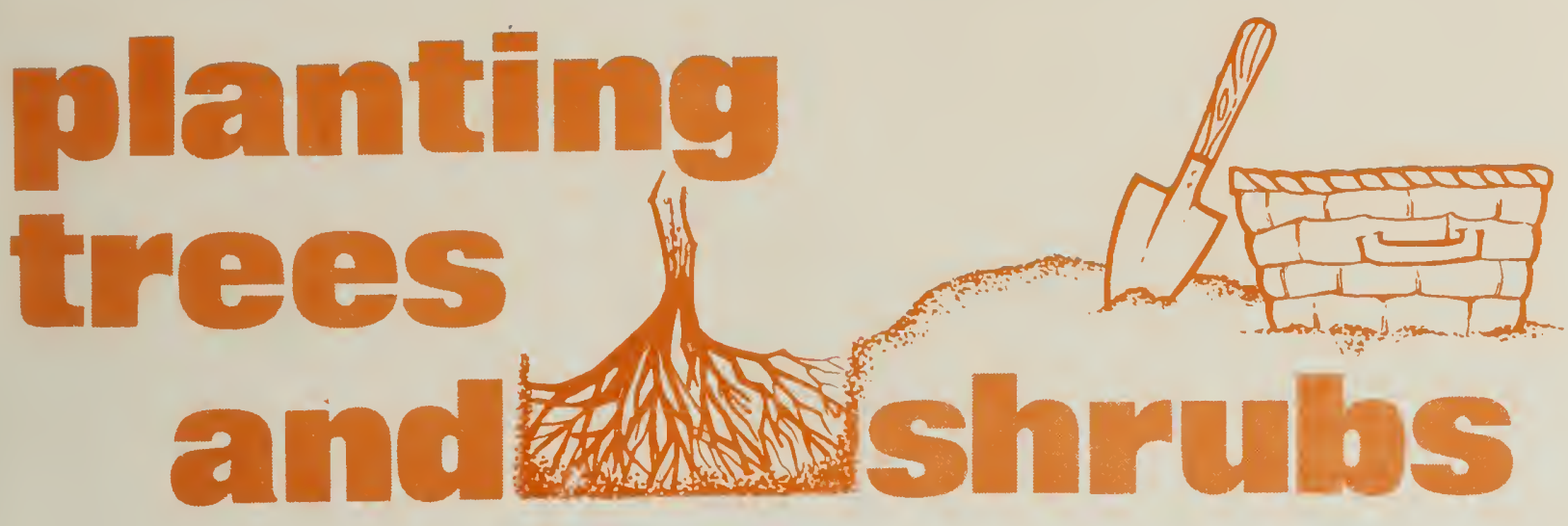

T. J. Cole

Research Station, Ottawa, Ontario

PUBLICATION 1679

WHEN TO PLANT

Deciduous and evergreen trees and shrubs can be planted in either spring or fall. Deciduous plants can be moved in the spring, as soon as the frost is out of the ground, or at any time until the new foliage is partly unfurled. In the fall, they can be planted from the time the leaves start to turn color until the soil freezes.

Although all trees and shrubs can be moved during either season, those with soft wood (such as poplars, willows, or birches) become established better if they are moved in the spring.

Evergreens should be moved earlier in the fall than deciduous plants. They need to be in their new location at least 6 weeks before the ground freezes, so that they can form new roots. In the spring they can be planted up to 4 weeks after deciduous trees have opened their leaves, provided they receive adequate water.

\title{
DIGGING THE PLANT
}

Although you will usually be concerned with planting trees and shrubs purchased from a nursery, you may occasionally have to transplant plants within your garden. When you dig up a plant, retain as much of the root system as possible. Deciduous plants that have been growing for only 3 or 4 years may be moved with their roots bare. Those that have been in place for a long time, and all evergreen plants, can be successfully moved only if a ball of soil is left around the roots.

After digging, protect the exposed roots with moist burlap or newspaper or with polyethylene sheeting.

\section{PREPARING THE HOLE}

Dig the new hole large enough to take the root system without crowding or folding the roots. Allow about $15 \mathrm{~cm}$ of space on all sides of a plant with bare roots or a small root ball. If the plant has a large root 


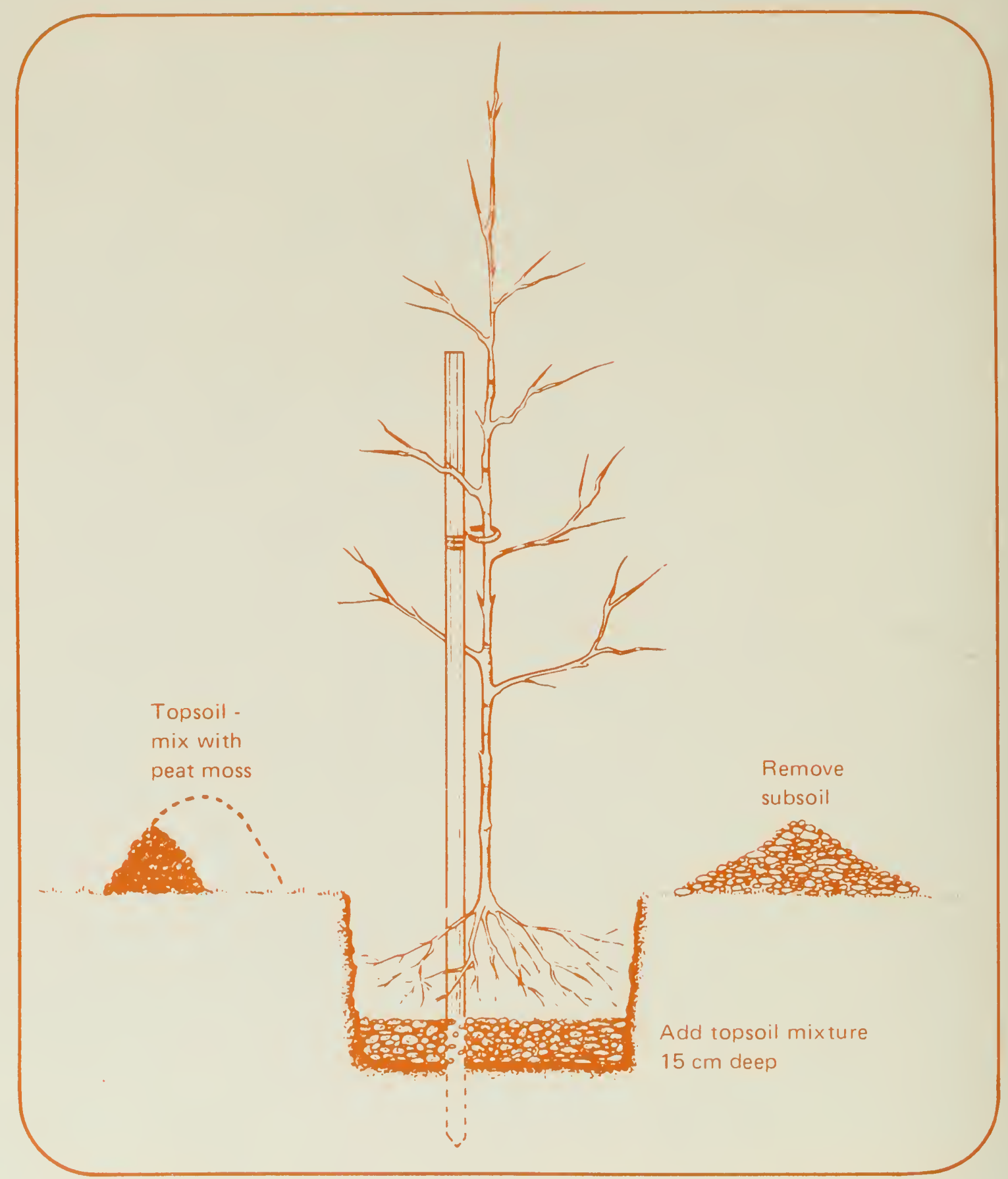

Fig. 1. How to plant a tree.

ball (over $1 \mathrm{~m}$ in diameter), allow about $30 \mathrm{~cm}$ all around.

When you dig the hole, retain the topsoil and discard any poor subsoil (Fig. 1). Mix the topsoil, and any additional soil needed, with about one-fourth by volume of peat moss, leaf mold, or well-rotted manure. If the soil is poor add a fertilizer such as 6-9-6 or 7-7-7 at $1 \mathrm{~g} / \mathrm{L}$, before mixing.

\section{HOW TO PLANT}

Plants purchased from a nursery are usually wrapped in plastic or kraft 


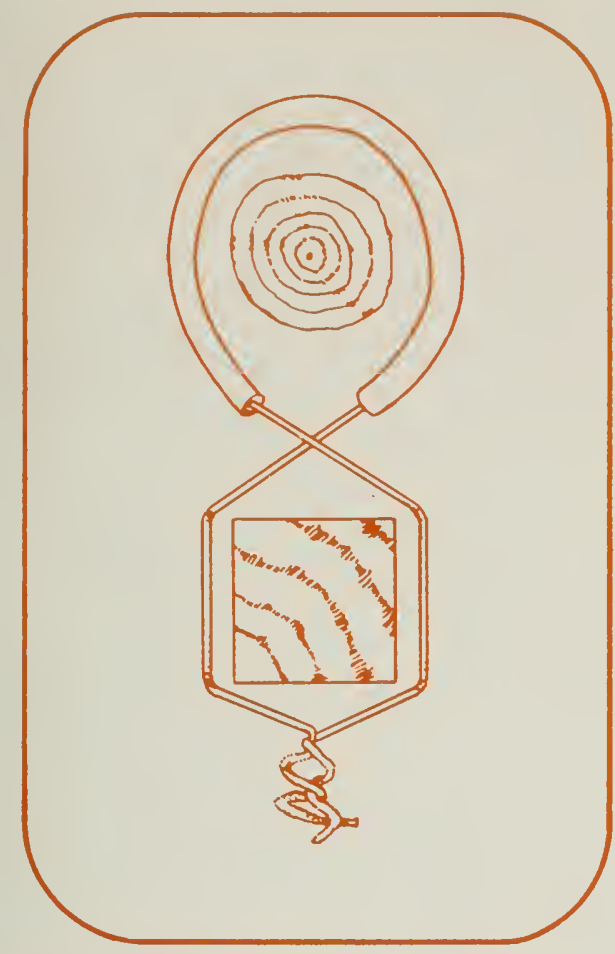

Fig. 2. One way to tie a tree to a support.

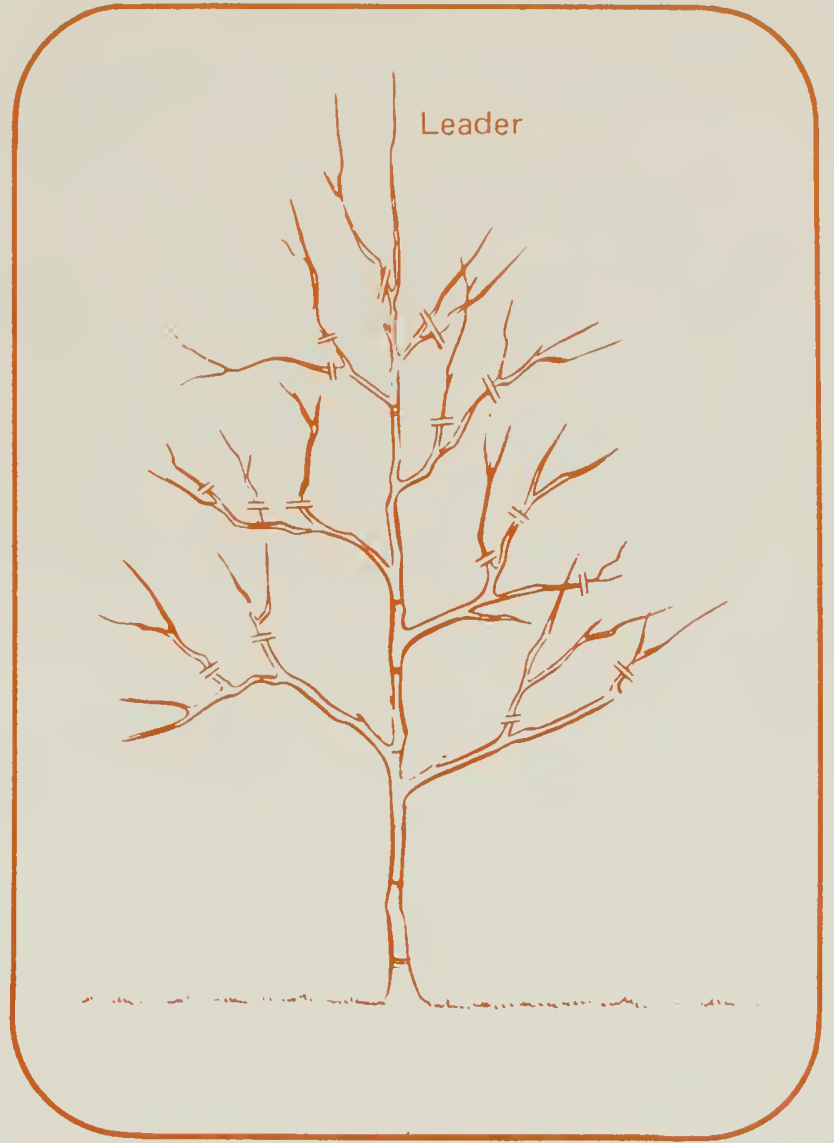

Fig. 3. How to prune a deciduous tree. Double lines show where to cut.

paper if they are bare rooted, or in burlap if they have a root ball. Carefully remove the wrapping from bare-rooted trees and shrubs and remove any other packing material such as excelsior. Trim back broken roots with sharp pruning shears. Trees with a burlap wrapping should be planted with their root ball still wrapped.

Set the plant in the hole with the old soil mark on the stem about $3 \mathrm{~cm}$ below soil level. Drive in a stake or other support if required (see "Supports for Trees", below), and start filling the hole. Work the soil down between the roots or under the curve of the root ball, firming it from time to time to avoid air pockets.

With burlap-wrapped plants, when the hole is about two-thirds full, untie the burlap from the base of the stem and spread it out in the hole.

With any kind of plants, finish filling the hole and tread the soil down firmly, leaving a slight depression. Water thoroughly and continue to water as required during the first season.

A mulch spread around transplanted trees and shrubs helps retain moisture and prevent growth of weeds.

\section{SUPPORTS FOR TREES}

Shrubs do not require any support, but all trees should be supported with a $5 \times 5 \mathrm{~cm}$ stake at the time of planting. The stake should be 2.5 to 
$3 \mathrm{~m}$ long, with the bottom third treated with a preservative (Fig. 1).

Large evergreens should be braced by two stakes placed on opposite sides of the root ball and joined with a cross strut, to which the tree is attached. Medium or large trees ( $3 \mathrm{~m}$ or more in height) are best supported by guy wires to prevent them from swaying in the wind.

Fasten the tree to the support with a commercial tree tie or a length of heavy wire (such as a coat hanger) passed through a piece of garden hose. Loop the tie round the tree, cross the ends, then twist them round the stake (Fig. 2). You will need to check all fastenings twice during the growing season and loosen them as required.

\section{PRUNING AFTER PLANTING}

If you have planted a deciduous shrub, prune off one-third of the previous year's growth. Remove any weak or thin branches.

Trim deciduous trees by removing about one-quarter of the top growth. DO NOT cut out the main leader (Fig. 3).

Evergreens planted in the spring should be clipped lightly. Do not trim the leader of an upright-growing type. If you plant evergreens in the fall, water them thoroughly and then, just before freeze-up, spray them with an antidesiccant to help them retain moisture during the winter. Such products are available at your local garden center.

PUBLICATION 1679, available from

Communications Branch, Agriculture Canada, Ottawa K1A OC7

(C) Minister of Supply and Services Canada 1980

Cat. No. A53-1679/1979 ISBN: 0-662-10286-X

Reprinted $1981 \quad 20 \mathrm{M}-9: 82$

Cette publication est aussi disponible en français. 